\title{
Respiration in a New Tuber Crop, Apios americana
}

\author{
M.E. Musgrave ${ }^{1}$ and W.J. Blackmon ${ }^{2}$ \\ Louisiana Agricultural Experiment Station, Louisiana State University Agricultural Center, Baton Rouge, \\ LA 70803 \\ Additional index words. alternative respiration, cyanide-resistant respiration, alternative crop
}

\begin{abstract}
The objective of this study was to investigate the respiratory pathways in the underground storage tissues (tubers, fleshy roots, and rhizomes) of Apios americana Medikus (apios). Freshly sliced tubers of experimental breeding lines expressed variable capacities for alternative respiration, depending on genetic background, although the alternative respiratory pathway was not engaged in any of the apios tissues tested. The capacity of the alternative pathway present upon slicing was consistent with genetic line over the 5 years of the study. Respiration patterns of tubers and fleshy roots were comparable within a genetic line; however, substantial differences were found in the respiration of the nonthickened sections of rhizomes compared with the storage tubers. Total respiration of stored rhizomes was high (up to $2.7 \mu \mathrm{l} \mathrm{O}_{2} / \mathrm{g}$ per rein) compared to that of tubers (up to $0.9 \mu \mathrm{O}_{2} / \mathrm{g}$ per min). Rhizome tissue respiration had a large capacity for alternative respiration $(40 \%-60 \%$ of total respiration), while tuber tissue had $0 \%$ to $73 \%$ alternative respiration, depending on genetic source. Epidermal layers, obtained from tubers that lacked a capacity for alternative respiration after slicing, had alternative respiration rates comparable to those of rhizomes. Furthermore, the alternative pathway could be induced in these tubers through conventional aging techniques. Etiolated shoots and rhizomes growing from these tubers also had an alternative respiration capacity that was half of the total rate. These results demonstrate that, although the capacity for alternative respiration is present in tissues of apios, freshly sliced tubers may or may not exhibit this pathway depending on genetic background. This attribute maybe significant as apios undergoes further domestication.
\end{abstract}

Apios is a tuber-producing, viny legume that was used as a food throughout the eastern United States by native North Americans and is being domesticated by researchers at the Louisiana Agricultural Experiment Station (Blackmon and Reynolds, 1986; Reynolds et al., 1990). Apios is of interest because of the high nutritional quality of the storage tissues (Wilson et al., 1987) and its potential in the gourmet food and natural products markets. Numerous accessions collected from the native range of the species are being evaluated and interbred and, over the past 10 years, significant progress has been made in tuber size and yield per plant.

Respiration by underground storage organs is important horticulturally because of its implications for decline in vigor, storage quality, and wounding. Plant tissue respiration may be cyanide sensitive (cytochrome pathway) or cyanide resistant (alternative pathway) (Lance, 199 1). Electron transport through the alternative oxidase results in heat production by the fleshy in florescences of species of Araceae, facilitating attraction of insect pollinators. Although the purpose of the alternative pathway in nonthermogenic organs is not known, much attention has been given to consequences of a potential loss of energy to the plant when the alternative pathway is used, since two sites of energy conservation are bypassed. However, a positive role has also been postulated, since the alternative pathway might provide au energy overflow whenever the cytochrome pathway is limited, allowing the continued processing of carbon skeletons.

Theologis and Laties (1980) described the partitioning of these two respiratory pathways in the storage tissues of 18 different horticultural crops. They found two categories of respiratory behavior: 1) those tissues that initially have low or absent alternative respiration and develop an active pathway after slicing and

Received for publication 21 Oct. 1994. Accepted for publication 10 Feb. 1995. Approved for publication by the director of the Louisiana Agricultural Experiment Station as paper \#903-38-8005. The cost of publishing this paper was defrayed in part by the payment of page charges. Under postal regulations, this paper therefore must be hereby marked advertisement solely to indicate this fact.

'Associate professor, Dept. of Plant Pathology and Crop Physiology.

${ }^{2}$ Professor, Dept. of Horticulture. aging (Irish potato type) 2) and those tissues that initially have large amounts of alternative respiration and lose activity of the pathway with slicing and aging (sweetpotato type). The purpose of our investigations was to compare the respiratory characteristics of apios with these well-studied storage tissues.

Apios represents an ideal material for this type of study. Although tubers are the most common storage organ produced, fleshy storage roots may also occur, and these are common in seedling-derived plants (Fig. 1). Using apios it is possible to compare respiration of ontogenetically different storage organs within the same plant. With the large number of accessions available, it is also possible to compare genetically different material that is at the beginning of the domestication process.

\section{Materials and Methods}

Plant material. Tuber and rhizome materials from 1987-89 and 1993 field tests were provided for these studies by B. Reynolds, Louisiana Agricultural Experiment Station, Baton Rouge. Materials were stored in loosely sealed plastic bags at 4-10C until use (26 months after harvest). Experimental lines LA85-006 and LA85034 were used for most of the experiments. Line LA85-006 produces numerous small light-skinned tubers on short rhizomes. Multinode or fused tubers are common. LA85-034 produces large single-node tubers. Rhizomes are longer and skin color is darker than for LA85-006. In 1989, four additional selections were examined after comparing their tuber morphologies with those of the previously studied types. Morphological characteristics of tubers of the selected lines and their geographical origins are listed in Table 1. In 1993, respiration measurements of lines LA85-034, LA85-006 and selected lines from open-pollinated crosses on these lines were compared to test for stability of the trait over time and its potential heritability.

Tissue preparation. Tissue samples from tubers or fleshy roots were obtained by cutting 5-mm-diameter cylinders from fleshy tissues with a cork borer and cutting these into 2-mm thick discs. Rhizomes were cut into $1 \times 2 \times 4$-mm pieces. Each manometer flask received $0.8 \mathrm{~g}$ tissue. Other preparations of tissues are described below. 


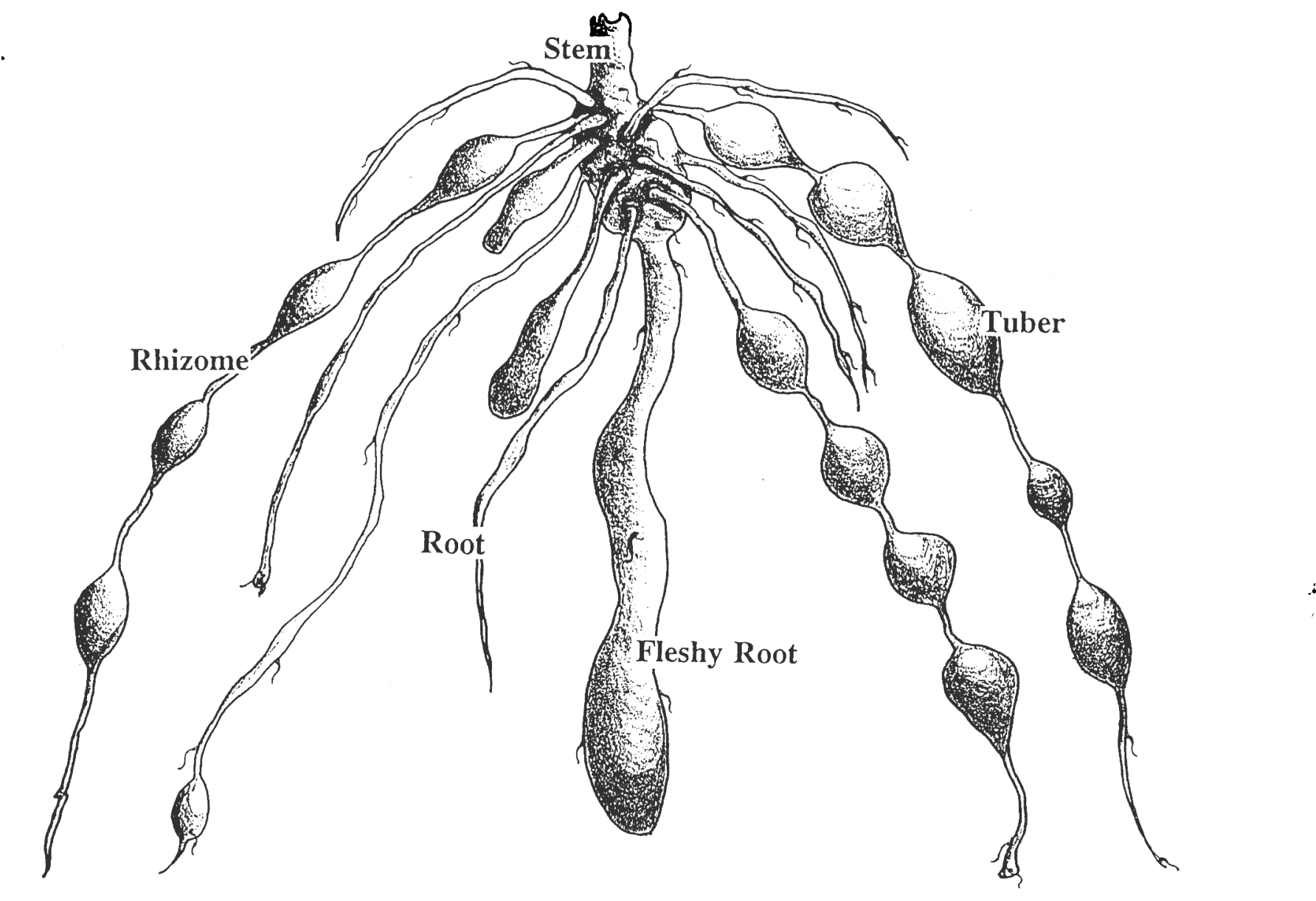

Fig. 1. Diagrammatic representation of a generalized underground system from an apios plant. Note the presence of tubers (single node, here) on rhizomes. The thickened storage roots are less common and occur most often from plants originating from seeds.

Tuber discs were aged by placing in beakers of distilled water through which air was bubbled for up to $48 \mathrm{~h}$. After aging, discs were washed and blotted dry before use in experiments. Because of the similarity between rhizome respiration and the respiration of small diameter tubers, interior (prepared as described above) and exterior (discs prepared from outer $2 \mathrm{~mm}$ of tissue) tissues of the large tuber producer, line LA85-034, were compared. To obtain etiolated shoots for respiration measurements, tubers were sprouted in dark chambers lined with moistened seed germination paper. Material sprouted for respiration studies was used 8-14 days after initiation of sprouting. Actively growing rhizomes were dug from the 1988 field study described in Musgrave et al. (1991), washed, and used in respiration studies as described below.

Respiration measurements. Respiration studies were conducted using Gilson differential respirometers equipped with 15 -ml singlearm reaction vessels. Aliquots of $20 \% \mathrm{KOH}(0.2 \mathrm{ml})$ were added to the center well of each vessel to absorb carbon dioxide. Oxygen consumption was monitored using standard manometric techniques (Umbreit et al., 1957). After a 15-min incubation period with the inhibitors (see below), the volumometers were closed. Rates were determined over the next hour by measuring volume changes at 10-min intervals and deriving the slope from a linear regression of the data for each flask.

Potassium phosphate buffer ( $2 \mathrm{mM}, \mathrm{pH} 5.9)$ was used in the reaction flasks $(2 \mathrm{ml})$ and for making stock solutions of the inhibitors salicylhydroxamic acid (SHAM) and $\mathrm{NaN}_{3}$. Concentrations of SHAM and $\mathrm{NaN}_{3}$ needed to fully inhibit the alternative and cytochrome respiratory pathways were determined by titration experiments in which SHAM was dissolved in dimethyl sulfoxide.
After it was determined that $3 \mathrm{~mm}$ was the appropriate concentration for both inhibitors, SHAM was dissolved in a small amount of absolute ethanol before adding it to the phosphate buffer. This amount of ethanol was determined to have no effect on respiration.

Engagement of the alternative pathway $(\rho)$ was determined by comparing rates in buffer with those in buffer plus SHAM alone. No evidence of engagement was found in any of the tissues assayed, whether fresh or aged. Therefore, the study focused on the capacity of the alternative pathway $\left(\mathrm{V}_{\text {att }}\right)$, determined by subtracting rates in the presence of SHAM and $\mathrm{NaN}_{3}$ from rates in $\mathrm{NaN}_{3}$ alone. Total respiration, VT, was the rate in buffer alone. Since $p$ was $0, \mathrm{~V}_{\text {cy }}$, the capacity of the cytochrome pathway, was the difference between the total respiration rate and the rate in the presence of azide. The tissues had residual respiration rates $\left(\mathrm{V}_{\text {res }}\right)$ in the range of $20 \%-30 \% \mathrm{~V}_{\mathrm{T}}$. Alternative respiration is expressed as a percentage of total respiration (which includes $\mathrm{V}_{\mathrm{res}}$ ).

\section{Results}

Tubers from lines LA85-006 and LA85-034 produced in the same field in 1987 had comparable total respiration rates when freshly sliced and during a timecourse of aging of discs up to $48 \mathrm{~h}$ (Fig. 2). The capacity for alternative respiration, however, was essentially absent in the freshly sliced tubers of line LA85-034, whereas line LA85-006 initially had about $40 \%$ alternative respiration capacity. After $48 \mathrm{~h}$ of aging, both lines exhibited about $40 \%$ alternative respiration although their total respiration rates had more than doubled.

Total respiration was constant across tuber lines (Table 1). The 


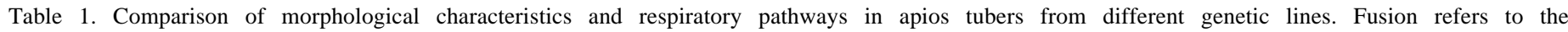

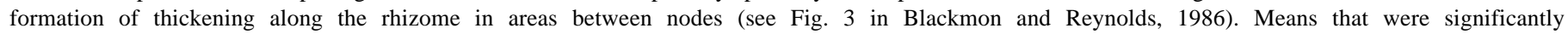
different at the 0.05 level as determined by Newman Keul's test following ANOVA are indicated by different letters.

\begin{tabular}{|c|c|c|c|c|c|}
\hline \multirow[b]{2}{*}{ Line } & \multirow[b]{2}{*}{ Fusion } & \multirow{2}{*}{$\begin{array}{l}\text { Diam } \\
(\mathrm{cm})\end{array}$} & \multicolumn{2}{|c|}{$\begin{array}{c}\text { Respiration }^{2} \\
\left(\mu \mathrm{l} \mathrm{O}_{2} / g \text { per min }\right)\end{array}$} & \multirow[b]{2}{*}{$\% \mathrm{~V}_{\text {att }}(\%)$} \\
\hline & & & $\mathrm{V}_{\mathrm{T}}$ & $\mathrm{V}_{\text {alt }}$ & \\
\hline${\mathrm{LA} 85-006^{y}}^{y}$ & Common & $1.6 \mathrm{a}$ & $0.85 \mathrm{a}$ & $0.37 \mathrm{bc}$ & 44 \\
\hline Chatham $\# 5^{y}$ & Common & $1.7 \mathrm{a}$ & $0.65 \mathrm{a}$ & $0.46 \mathrm{c}$ & 71 \\
\hline Chatham $\# 9^{y}$ & Common & $1.4 \mathrm{a}$ & $0.70 \mathrm{a}$ & $0.24 \mathrm{~b}$ & 34 \\
\hline LA $85-034^{x}$ & Rare & $4.0 \mathrm{~d}$ & $0.74 \mathrm{a}$ & $-0.01 \mathrm{a}$ & -1 \\
\hline Lecompte $\# 5^{\mathrm{w}}$ & Rare & $2.1 \mathrm{~b}$ & $0.80 \mathrm{a}$ & $0.40 \mathrm{c}$ & 50 \\
\hline Maringouin \#2w & Rare & $2.6 \mathrm{c}$ & $0.84 \mathrm{a}$ & $0.28 \mathrm{~b}$ & 33 \\
\hline
\end{tabular}

${ }^{2}$ Refer to Materials and Methods for calculation of $\mathrm{V}_{\mathrm{T}}$ (total respiration), $\mathrm{V}_{\text {alt }}$ (alternative respiration capacity), and \% $\mathrm{V}_{\text {all }}$.

'Germplasm originated from geographical areas near Chatham, La.

'Germplasm originated from the geographical area near Grand River, La.

${ }^{\text {w}}$ Germplasm originated from the geographical area near Lecompte or Maringouin, La, respectively.

capacity for alternative respiration, however, varied significantly depending on genetic source. There was no relationship between tuber morphology (size, degree of nodal fusion) and the relative capacity for alternative respiration in the six sources studied.

The difference in capacity for alternative respiration between tubers of LA85-006 and LA85-034 was not apparent in actively growing material obtained as dark grown shoots sprouted from tubers, or as rhizomes dug up from plants in the field. Respiration by etiolated shoots and rhizomes of line LA85-034 had an alternative pathway component and was not statistically different from that of line LA85-006 (Table 2). The actively growing rhizome material had a slightly higher total respiration rate than the mature rhizomes harvested and stored with tubers (Table 2, Fig. 3A).

Rhizomes, regardless of the germplasm source, had a higher total respiration rate and a higher capacity for alternative respiration than tubers (Fig. 3A). The capacity for alternative respiration of tubers was variable depending on the genetic source. In terms of percentage of alternative respiration, fleshy root respiration was similar to the tuber respiration. Interestingly, the outer layers of LA85-034 tubers had alternative respiration capacity although it was absent from the inner tissues (Fig. 3B).

Respiration and size data obtained for LA85-006 and LA85034 in 1993 (Table 3) were very similar to the 1988 data (Table 1). The open-pollinated offspring of LA85-006 (LA88-807) had a significantly lower total respiration rate, a very high capacity for alternative respiration, and relatively small tuber size (Table 3). Two large tubered lines, LA89-1 120 and LA91-1816, open-pollinated seedlings of LA85-034 and LA88-807, respectively, had the same trends in respiratory pathways as those initially described for LA85-006 and LA85-034.

\section{Discussion}

Most underground storage tissues studied to date have respiration that uses the cytochrome pathway when the organ is freshly sliced, while comparatively few exhibit large capacities for alternative respiration (Theologis and Laties, 1980). Apios fits into both of these categories, depending on germplasm source. As a plant is brought into domestication, much of the genetic diversity that existed in its original germplasm pool is discarded (Vietmeyer, 1986),. Perhaps his explains why observations based on the underground storage tissue of our horticultural crops indicate a single respiration type for each crop, while apios tuber respiration appears to have both categories of tissue respiration.

The significance of alternative respiration in plants has been debated for sometime and was recently reviewed by Lance (1991). Respiratory pathways in underground storage organs change with vigor, storage time, wounding, and pathogen activity. It has been observed, for example, that the LA85-006 line of tubers sprouts prematurely in storage, whereas the LA85-034 line does not creased alternative respiration to decreased sprout vigor in aged creased alternative respiration to decreased sprout vigor in aged seed-potato tubers. Lange (1970) reported far greater amounts of alternative respiration in periderm-producing potato slices than in

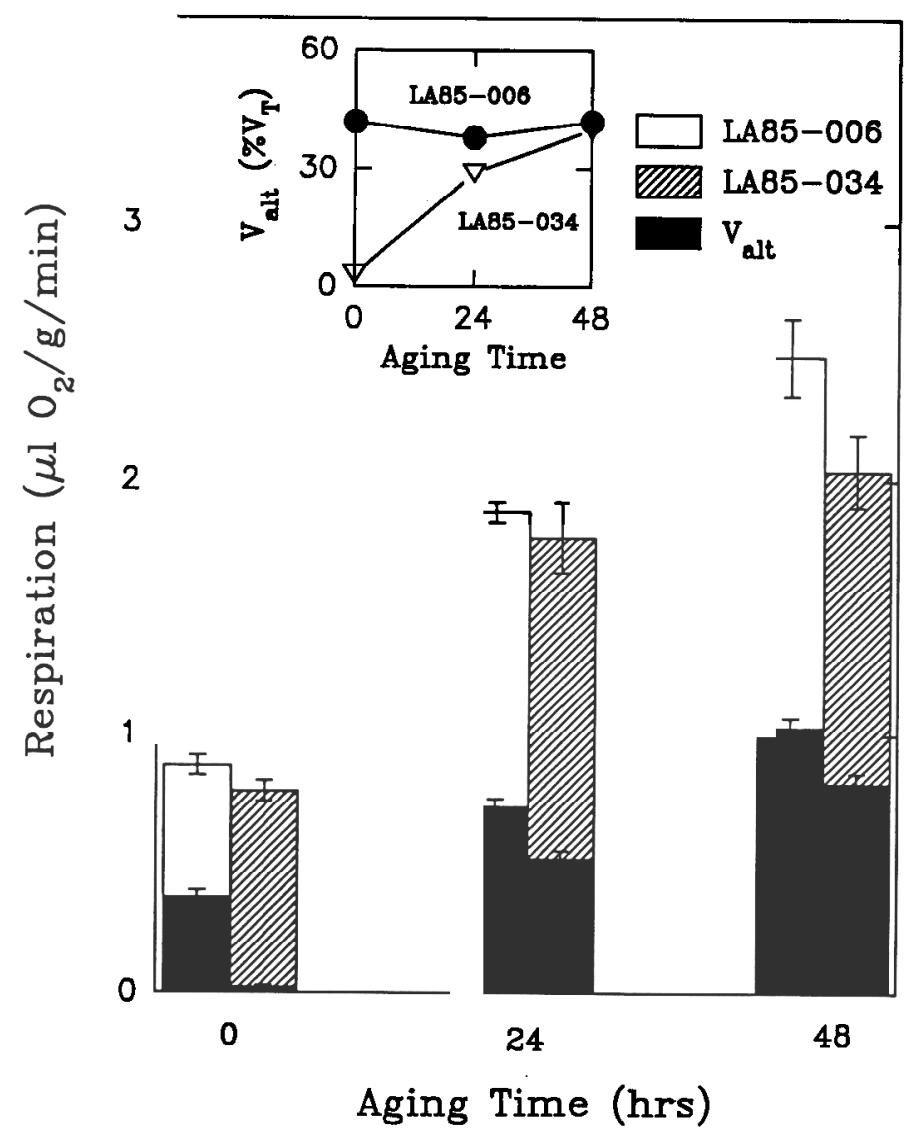

Fig. 2. Effects of aging on respiration in two lines of apios: LA85-006 and LA85034 . The capacity for alternative respiration $\left(\mathrm{V}_{\text {all }}\right.$ in $\mu \mathrm{l} \mathrm{O} / \mathrm{g}$ per min) for each time period is indicated by the solid bars within the bars depicting total respiration (VT). Standard error bars are shown around the mean $(n=8)$. The inset shows the change in alternative respiration capacity with time of aging, with alternative respiration capacity expressed as a percent of the total respiration. 


\begin{tabular}{lccc}
\hline \hline & \multicolumn{2}{c}{ Respiration $(\mu \mathrm{l} \mathrm{O} / \mathrm{g}$ per min $)$} & $\mathrm{V}_{\text {alt }}(\%)$ \\
\cline { 2 - 3 } & $\mathrm{V}_{\mathrm{T}}$ & $\mathrm{V}_{\text {alt }}$ & $\mathrm{NS}$ \\
Material & & $\mathrm{NS}$ & 41 \\
$\quad$ Shoots & 8.36 & 3.40 & 51 \\
Rhizomes & 2.93 & 1.50 & $\mathrm{~N}$ \\
Line & $\mathrm{NS}$ & $\mathrm{NS}$ & 41 \\
LA85-006 & 5.70 & 2.35 & 46 \\
LA85-034 & 5.58 & 2.57 & 46 \\
\hline
\end{tabular}

*Significant $(P<0.05)$ effect of material source was detected by ANOVA.

callus-producing tissues. Tissue type may also be a determining factor in respiration type. Theologis and Laties (1 980) found more cyanide resistance in respiring phloem tissue than in xylem.

In our experiments with apios, capacity of the alternative pathway $\left(\mathrm{V}_{\text {att }}\right)$ in tuber tissue varied with genetic source. Engagement ( $\mathrm{p}$ ), determined by addition of SHAM, was always assessed to be $O$, suggesting that these different capacities of alternative respiration are not contributing to total respiration in vivo. However, recent work using the oxygen isotope discrimination technique has shown that inhibitor studies may not accurately determine alternative pathway engagement (Ribas-Carbo et al., 1994).

Tuber tissue of line LA85-034 lacked alternative respiration capacity when freshly sliced. However, closely connected rhizome tissues and sprouts from these tubers had art alternative respiration capacity of about $50 \%$ of the total rate. Since the epidermal tissue of this tuber also had alternative respiration equivalent to that of the rhizome, the tuber respiration seems to be a consequence of tissue differentiation. This trait was not a requisite for enlargement, however, as shown by LA89-1120 (Table 3), which belongs to the LA85-006 respiration group, but was the largest of the tuber types examined in this survey.

Another way of approaching the question of whether size of storage organ is related to respiratory pathway patterns was to compare the respiration of storage roots, tubers, and nonthickened rhizomes within the same genetic material (Fig. 3A). Rhizome material was high in total respiration and alternative respiration in lines LA85-006, LA85-034, and open pollinated offspring. Tuber tissue was lower in alternative respiration than rhizome material regardless of source. Fleshy roots from material with low alternative respiration rates in the tuber also had low alternative respiration (open pollinated seedling), while the LA85-006 fleshy roots had a higher percentage of alternative respiration, similar to the

3.0

A

B

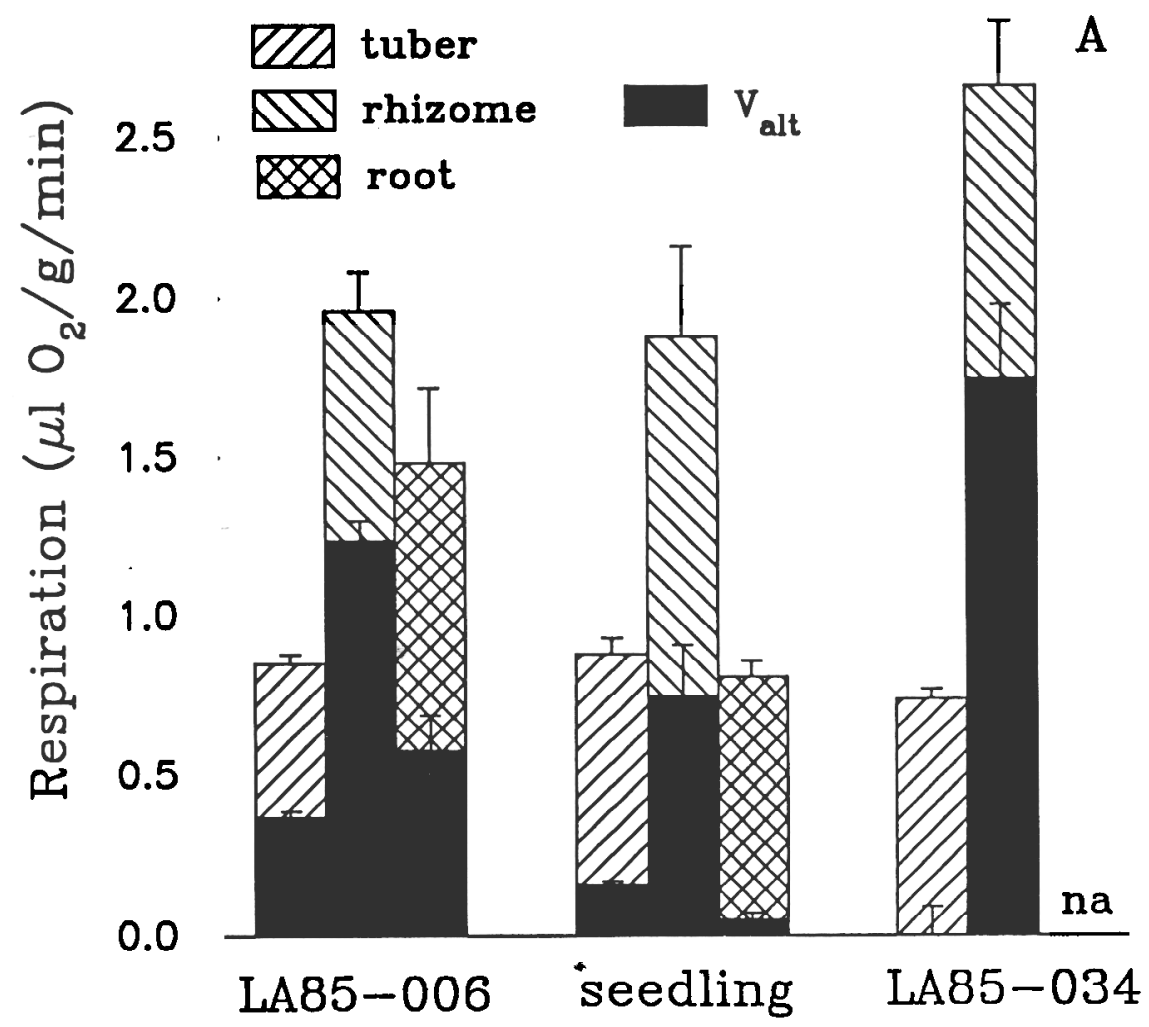

\section{Outer}

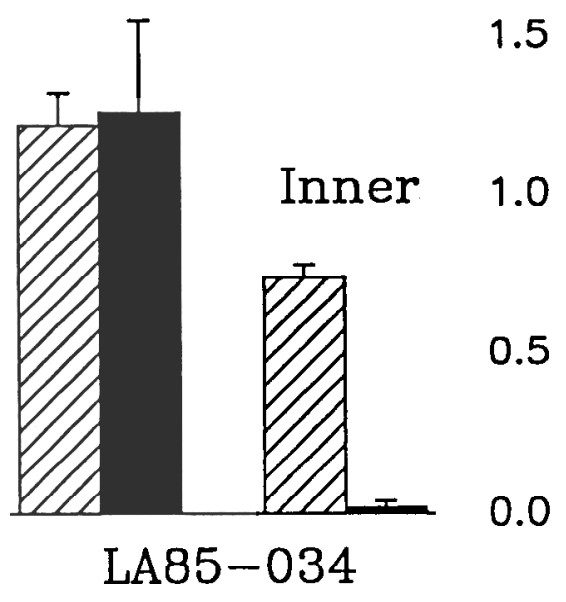

Fig. 3. Total respiratic rates, $\mathrm{V}_{\mathrm{T}}$ (stippled bars), and capacity of the alternative pathway, $\mathrm{V}_{\text {at }}$ (solid bars), for different types of tissue. Standard error bars are shown around the mean $(n=6)$. (A) Comparison of respiratory components depending on tissue source (tuber, rhizome or fleshy root, see Fig. 1) in selected apios lines (propagated from tubers) and from a seedling (probable open-pollinated cross) from the parental lines. (B) Comparison of respiratory components depending on which part of the LA85-034 tuber was used to prepare discs. 
Table 3. Comparison of tuber size and respiratory pathways in apios tubers from different genetic lines (1993). Diameter, total respiration rate $\left(\mathrm{V}_{\mathrm{T}}\right)$, and alternative pathway capacity $\left(\mathrm{V}_{\text {atl }}\right)$ means that were significantly different at the 0.05 level as determined by Newman Keul's test following ANOVA are indicated by different letters.

\begin{tabular}{|c|c|c|c|c|c|}
\hline \multirow[b]{2}{*}{ Line } & \multirow[b]{2}{*}{ Origin } & \multirow{2}{*}{$\begin{array}{l}\text { Diam } \\
(\mathrm{cm})\end{array}$} & \multicolumn{2}{|c|}{$\begin{array}{c}\text { Respiration } \\
\left(\mu \mathrm{O}_{2} / \mathrm{g} \text { per tin }\right)\end{array}$} & \multirow[b]{2}{*}{$\mathrm{V}_{\text {alt }}(\%)$} \\
\hline & & & $\mathrm{V}_{\mathrm{T}}$ & $\mathrm{V}$ & \\
\hline LA85-006 & Chatham & $1.6 \mathrm{a}$ & $1.16 \mathrm{~b}$ & $0.52 \mathrm{~b}$ & 45 \\
\hline LA85-034 & Grand River & $3.8 \mathrm{c}$ & $0.97 \mathrm{~b}$ & $-0.01 \mathrm{a}$ & -1 \\
\hline LA88-807 & LA85-006 x OP & $2.9 \mathrm{~b}$ & $0.71 \mathrm{a}$ & $0.52 \mathrm{~b}$ & 73 \\
\hline LA89-1120 & LA85-034 x OP & $6.3 \mathrm{e}$ & $1.15 \mathrm{~b}$ & $0.43 \mathrm{~b}$ & 37 \\
\hline LA91-1816 & LA88-807 x OP & $5.1 \mathrm{~d}$ & $1.02 \mathrm{~b}$ & $-0.09 \mathrm{a}$ & -9 \\
\hline
\end{tabular}

${ }^{2}$ Open-pollinated seedlings.

amount in its tubers. This suggests that, regardless of ontogenetic source of the storage tissue, the respiration of the storage organ has a characteristic pattern based on the genetic background.

When subjected to an aging procedure, the tuber tissue of LA85-034 developed alternative respiration within 24 h (Fig. 2), as occurs in Irish potato. Theologis and Laties (1980) have postulated that membrane integrity is necessary for the functioning of the alternative pathway and that the mitochondrial membrane breakdown caused by slicing is repaired during aging. Hiser and McIntosh (1990) showed that, in potato, the alternative oxidase is an integral membrane protein synthesized de novo during aging of tissue slices. In contrast, apios line LA85-006 exhibited changes in respiration with aging that are characteristic of the sweetpotato.

Recent development of transgenic potato lines with overexpression or underexpression of alternative oxidase is making possible a better understanding of the role alternative respiration plays in these processes (Hiser et al., 1994). Apios then becomes an ideal vehicle for examining the impact of these respiratory pathway characteristics on horticulturally important traits. The existence of a number of lines of apios with different respiratory characteristics will make this type of study possible.

\section{Literature Cited}

Blackmon, W.J. and B.D. Reynolds. 1986. The crop potential of Apios americana- Preliminary evaluations. HortScience 21:1334-1336.

Hiser, C., N.R. Bowlby, and L. McIntosh. 1994. Two new approaches to the investigation of the alternative oxidase of potato. Plant Physiol. Suppl. 105:66.

Hiser, C. and L. McIntosh. 1990. Alternative oxidase of potato is an integral membrane protein synthesized de novo during aging of tuber slices. Plant Physiol. 93:3 12-3 18.

Lance, C. 1991. Cyanide-resistant respiration in plants, p. 141-153. In: M.B. Jackson, D.D. Davies, and H. Lambers (eds.). Plant life under oxygen deprivation. SPB Academic Publishing bv, The Hague, Netherlands.

Lange, H. 1970. Atmungwege bei vemarbenden und proliferierenden Gewebefragmenten der Kartoffelknolle. Planta 90: 119-132.

Mikitzel, L.J. and N.R. Knowles. 1990. Changes in respiratory metabolism during sprouting of aged seed-potato tubers. Can. J. Bet. 68:16191626.

Musgrave, M.E., A.G. Hopkins, Jr., and C.J. Daugherty. 1991. Oxygen insensitivity of photosynthesis by waterlogged Apios americana. Environ. Expt. Bet. 31: 117-124.

Reynolds, B. D., W.J. Blackmon, E. Wickremesinhe, M.H. Wells, and R.J. Constantin. 1990. Domestication of Apios americana, p. 436442. In: J. Janick and H. Shands (eds.). Advances in new crops. Timber Press, Portland, Ore.

Ribas-Carbo, M., L. Giles, S.A. Robinson, D. Yakir, J.N. Siedow, and J.A. Berry. 1994. Studies of the electron partitioning between the cytochrome and the alternative pathway in isolated mitochondria using a developed oxygen isotope discriminating system. Plant Physiol. Suppl. 105:27.

Theologis, A. and G.G. Laties. 1980. Membrane lipid breakdown in relation to the wound-induced and cyanide-resistant respiration in tissue slices. A comparative study. Plant Physiol. 66:890-896.

Umbreit, W.W., R.H. Burris, and J.F. Stauffer. 1957. Manometric techniques. Burgess Publishing Co., Minneapolis.

Vietmeyer, N.D. 1986. Lesser-known plants of potential use in agriculture and forestry. Science 232:1379-1384.

Wilson, P.W., F. Pichardo, J.A. Liuzzo, W.J. Blackmon, and B.D. Reynolds. 1987. Amino acids in the American groundnut (Apios americana). J. Food Sci. 52:224-225. 